\title{
Engineering geology investigation and numerical modelling design of the Ramp 12 highwall
}

\author{
B Roache Mining One Consultants Pty Ltd, Australia
}

AR Johnstone BHP, Australia

\begin{abstract}
The Goonyella Riverside Mine is located in the Bowen Basin of Queensland, Australia, and has been in constant operation since 1971. Seams of metallurgical coal are mined from a series of ramps (pits) using strip mining techniques and highwalls are formed by dragline excavation. A $750 \mathrm{~m}$ long, $100 \mathrm{~m}$ high, progressive highwall failure was monitored and safely managed at Ramp 12 during 2016. Engineering geology investigations commenced at this time to determine the mechanism of slope movement. The slope failure was attributed to a number of structural influences, most interesting of these being the overbank bedding structures combining with jointing in the interburden Permian sedimentary rock. A number of questions needed to be answered by site management, including how to stabilise and remove a large and actively moving highwall in a responsible and safe manner and to correctly account for the identified failure mechanism in design of the next highwall strip position. A three dimensional numerical approach that could account for the failure mechanism was selected and was used to back analyse the progressive development of the failure. The numerical model was then used to look forward and design the position and size of a stabilisation buttress and the highwall slope configuration for the advancing highwall. A full case study is presented, from identification and management of the slope instability, to developing an understanding of the failure mechanism, slope remediation, numerical modelling design and ongoing highwall performance of the redesigned pit highwall.
\end{abstract}

Keywords: case study, slope failure, numerical modelling

\section{Introduction}

The Goonyella Riverside Mine (GRM) is located towards the northern end of the Bowen Basin in Queensland, and is owned 50:50 by BHP and Mitsubishi. The mine produces high quality metallurgical coal from a series of open pits, using draglines and truck and shovel fleets for overburden removal. Coal production of over 15 million tonnes during the 2018 financial year was achieved through mining of three coal seams, known as the Goonyella Upper Seam (GUS), Goonyella Middle Seam (GMS) and Goonyella Lower Seam (GLS).

Mining is generally carried out by open pit strip mining techniques. This mining method progressively exposes the coal in $60 \mathrm{~m}$ wide strips, working down dip towards the east, with the pits oriented north-south. Pre-strip mining crews employ truck and shovel fleets to remove the softer materials on the highwall side of the pit, and draglines move overburden waste to the low-wall in-pit dump, as shown in Figure 1 . As there are three coal seams to be removed, the highwall configuration is offset to allow multiple mining areas in the same pit. There are currently eight active pits at the Goonyella Riverside Mine, with each about $1.5 \mathrm{~km}$ to $2 \mathrm{~km}$ in length. 


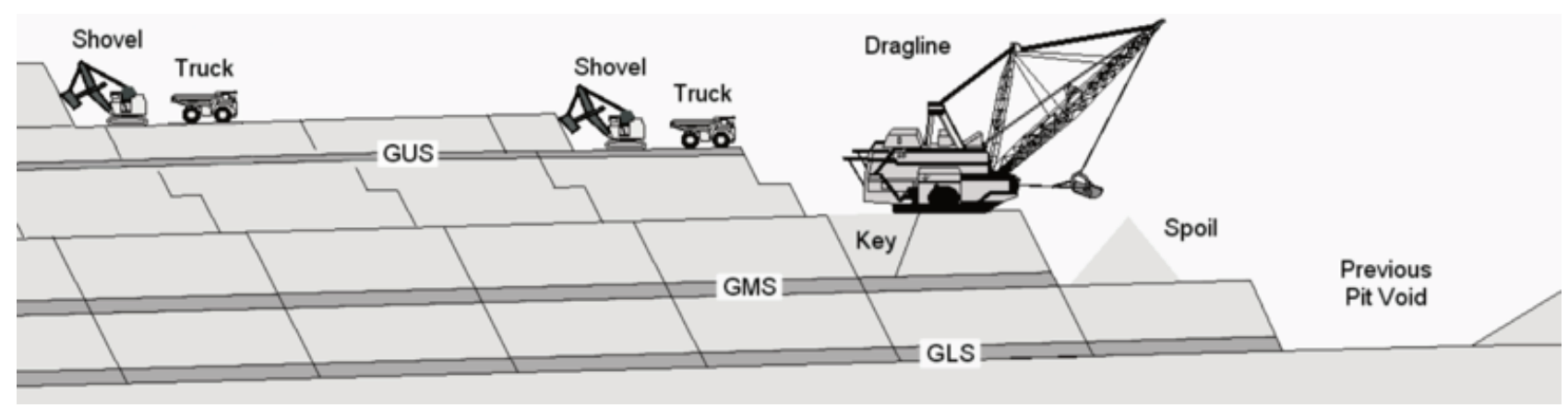

Figure 1 Goonyella Riverside Mine stripping operations

The Ramp 12 highwall between the GUS and GMS benches was first reported to be cracking and deforming in February 2016. The highwall continued to deteriorate into a progressively moving slope failure over a period of months and was $100 \mathrm{~m}$ high and $750 \mathrm{~m}$ in extent, as shown in Figure 2. The scale of the wall failure and the progressive nature of the slope movement presented challenges to safely stabilise and remove the failure. Following removal of the failure, it was important to correctly account for the identified failure mechanism in design of the next highwall strip position and maintain highwall stability. The Ramp 12 highwall was mined using truck and shovel methods, with a slope angle considered to be relatively conservative at $45^{\circ}$ between the GMS and GUS benches. Thrust faults, which intersect the slope and are associated with poorer rock mass conditions, were not initially considered to contribute to the observed failure.

In the strip before the highwall slope that would ultimately fail, the GMS highwall was exposed by the dragline in a presplit $65^{\circ}$ slope to approximately $30 \mathrm{~m}$ above GMS coal. Instability in the previous strip's GMS highwall was attributed to overbank bedding orientation being unfavourable. Thrust faults were not considered contributing to the observed instability due to the modelled proximity to the slope at that time. The GMS highwall was altered to a pre-strip $45^{\circ}$ toe to toe equivalent softwall slope, excavated in smaller flitches to achieve the desired wall angle of $45^{\circ}$. This design change was accommodated in what would have been the $30 \mathrm{~m}$ wide GMS highwall berm at the previous dragline horizon that allowed the presplit tail room. This change was absorbed by using up the $30 \mathrm{~m}$ wide presplit tail room berm, and other benches above the old dragline horizon were not affected by the design change.

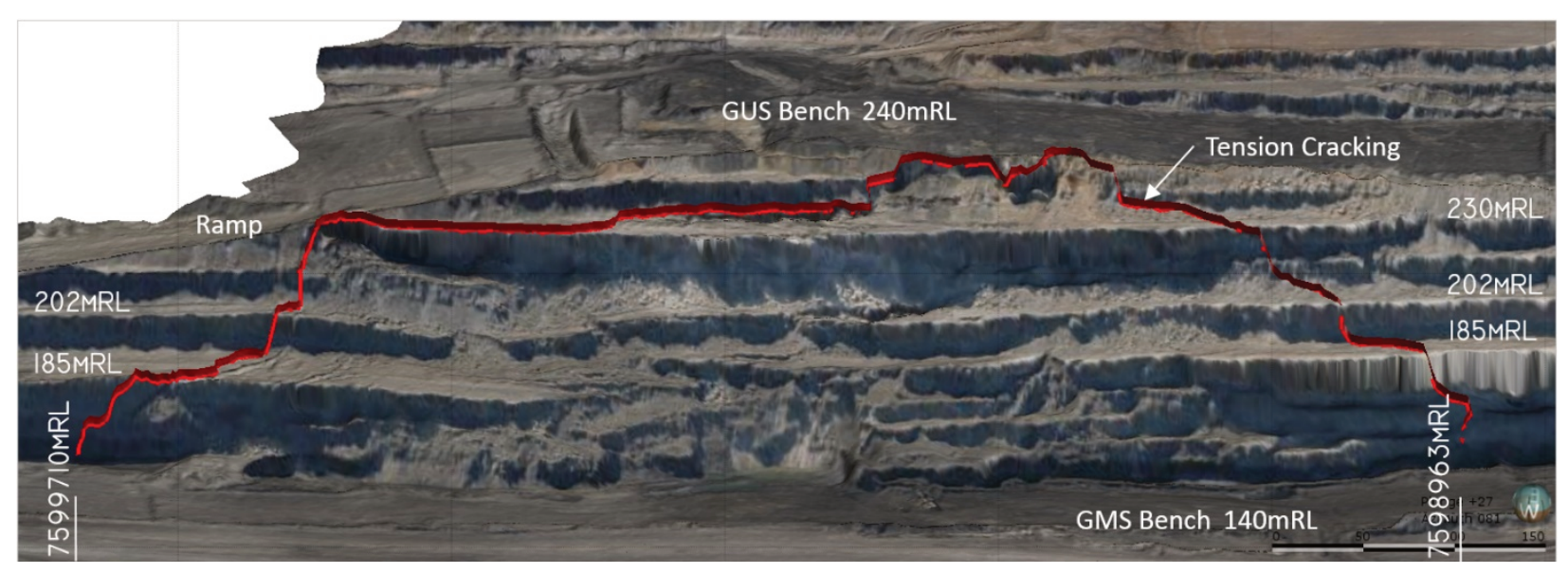

Figure 2 Front on view of the Ramp 12 highwall failure

Radar monitoring was commenced as a risk assessment control to allow operational management of the Ramp 12 highwall failure. This enabled mine operations to implement an excavation plan for GMS coal, at the same time as undertaking an engineering geology assessment to understand the failure key contributing factors. 


\section{Ramp 12 engineering geology}

The material between the GMS and GLS is fresh Permian rock. Permian rock at Goonyella usually consists of interbedded to interlaminated sandstones, siltstones, and claystones (sometimes carbonaceous) laid down as sheet-like beds which vary in thickness from $10 \mathrm{~mm}$ to more than $2 \mathrm{~m}$. The Ramp 12 Permian rock consisted of interbedded siltstones and sandstones, with a channel structure located immediately above the GMS, before transitioning to thicker sandstone beds. A carbonaceous band was observed the top of GMS.

A thrust fault was predicted to be present in the highwall. It was not clearly visible, however it was noted that the Ramp 12 GMS interburden was more fractured than observed in previous strips, and drove the original slope design of $45^{\circ}$, considered a more conservative design angle than usually applied. Bedding within the Permian rock is usually parallel to the coal seam dip. In some isolated locations the bedding can have local westerly dips, which are dipping into the pit void and clearly less favourable for slope stability. Bedding with westerly dips (into the pit void) are often referred to as 'overbank structures' and are thought to be caused by depositional events and possibly exacerbated by the effects of differential compaction during sedimentation. Overbank structures were clearly visible in the Ramp 12 Permian rock for about $25 \mathrm{~m}$ immediately above the top of GMS and can provide a basal release for block sliding failure or a more complex 'composite' wall failure, which is made up of movement on a number of different structures and failure through intact rock bridges (Simmons \& Simpson 2006).

Joints are the predominant form of discontinuity other than bedding and some joint planes may adversely affect the stability of highwalls by providing pitward dipping surfaces for sliding and also by acting as failure release surfaces and connecting surfaces for other discontinuities. In the case of Ramp 12, two near vertical joint orientations were clearly visible.

The overbank bedding was recorded during pit wall mapping at an average dip of $13^{\circ}$ into the pit. The overbank structures were considered a likely contributor to the development of wall failure, but detailed visual observation of the failure toe (at the GMS bench level) did not indicate any significant lipping, or buckling failure of GMS coal, as shown in Figure 3. This indicated that sliding on the carbonaceous layer at the top of the GMS coal was not the only cause of the advanced slope deformation that had moved metres over a period of months.

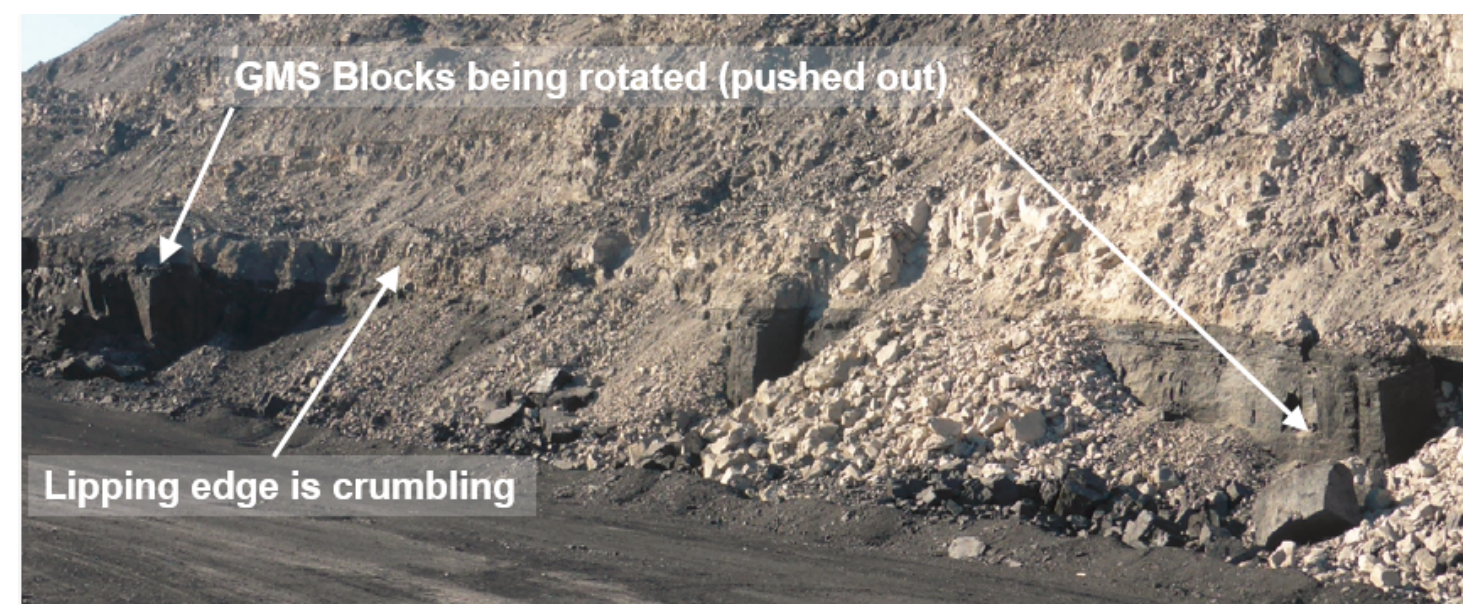

Figure 3 Observations from the Ramp 12 highwall at Goonyella Middle Seam (GMS) level

The Ramp 12 highwall deformation characteristics were monitored over a number of months. LiDAR survey data was regularly collected, as is general practice at the large Bowen Basin open pit coal mines. Interrogation of the LiDAR data enabled interpretation of the highwall deformation, which was determined to be bounded by structural controls. Tension cracks had formed on the two vertical joint sets at the GUS bench. The majority of slope deformation occurred in a shape that appeared to be an inverted wedge located at the southern end of the failure area, as shown in Figure 4. The deformation of the inverted wedge allowed further movement to occur deeper into the slope, on the same structure set combinations. 


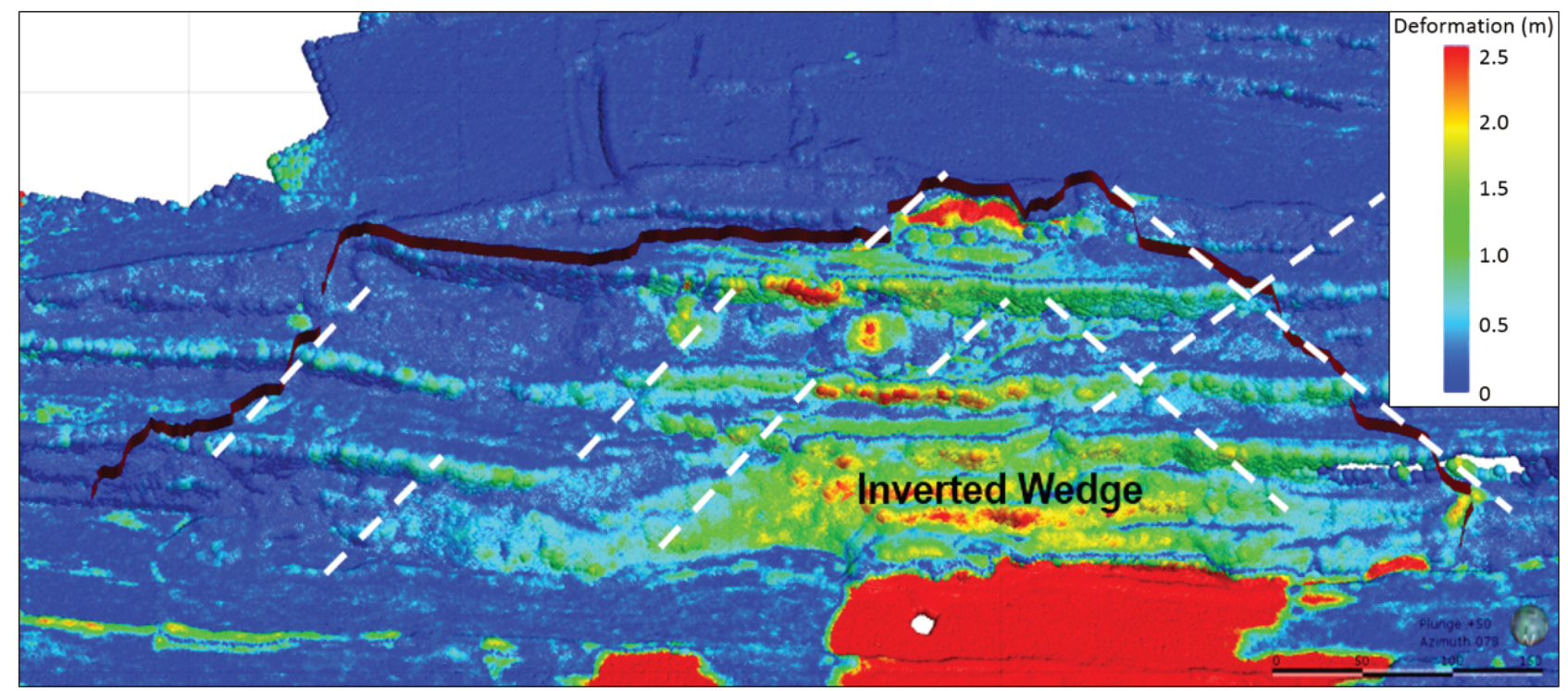

Figure 4 Ramp 12 highwall LiDAR scan deformation

Interpretation of the data indicated a large highwall failure, continuing to fail progressively with structural controls defining the slope into a number of movement zones. It was possible to describe the failure in a number of ways, but it can be thought of as a composite wedge, where three structure sets are combining to define the slope deformation. A simplified representation of the slope failure mechanism is shown in Figure 5.

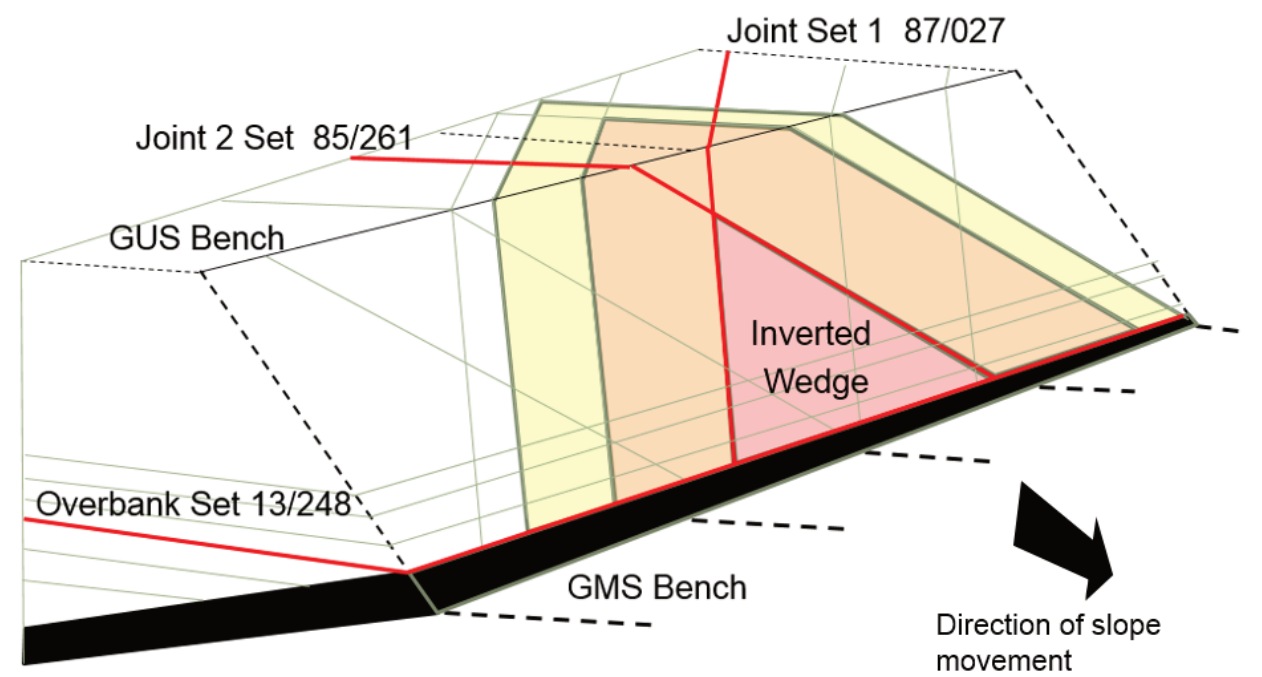

Figure 5 Ramp 12 highwall slope failure mechanism

\section{$3 \quad$ Mining the Ramp 12 failure}

Removing the highwall failure material was a requirement to meet the ongoing schedule for coal mining in Ramp 12. A main consideration was allowing safe access on the GMS bench for mining crews while the remaining coal was mined. The failure was still moving and excavation of the highwall required mine operations to be on top of the failure to either excavate, push or throw the failure material into the pit void. Two options were considered. Option 1 involved waiting for the failure to stabilise and then mine, but this option was discounted due to the unknown time frame required for the slope to fully stabilise. Option 2 involved stabilising the slope using a temporary buttress. The buttressing option was selected as the preferred approach as it allowed for mining crews to work on top of the failure as soon as the buttress caused the slope to stabilise. 


\subsection{Failure back-analysis}

A key step in the numerical assessment was to generate a back-analysis model to replicate the failure, in terms of the failure position, extents and strain. A three dimensional numerical back-analysis model using FLAC3D was undertaken to mimic the mechanism of failure and replicate the failure slope movement. The most significant input to the numerical model was the addition of the thrust fault to the model, as it restricted the failure to the area of interest. Where the fault was closer to the toe of the slope, it allowed for increased levels of displacement relative to other positions on the slope. This modelled observation means that the initial assumption that overbank structures were the main contributing factor in slope failure development were incorrect and it was instead the thrust fault and the overbank structures in combination causing failure.

The preferred modelling methodology was a continuum model, using the IUCM solver (Improved Unified Constitutive Method), described in detail by Vakili (2016). There are limitations on the level of complexity that a large-scale numerical model can handle, and simplification is required to either make the model run or produce results promptly. This methodology was selected due to constitutive models being much simpler and faster to set-up and run when compared to discontinuum models, but also because the IUCM can represent anisotropic layers in a continuum environment. It does this by explicitly including strength anisotropy in a ubiquitous joint model, which accounts for both rock matrix strength and the lower strength associated with the existence of an anisotropy plane (Vakili et al. 2014). The IUCM aims at collating and accounting for all experimentally and operationally documented rock mass behaviours as a function of the acting stresses and accumulated strain.

The overall model size focused on the highwall side of the Ramp 12 pit void. The pre-mining stress state and material parameters were defined from previous technical studies at the Goonyella mine. The material parameters were further adjusted during the back-analysis process and are shown in Table 1.

Table $1 \quad$ Material input parameters

\begin{tabular}{|c|c|c|c|c|}
\hline \multicolumn{2}{|c|}{ Rock unit } & \multirow{2}{*}{$\begin{array}{l}\text { Coal measure } \\
\text { rocks } \\
2.5\end{array}$} & \multirow{2}{*}{$\begin{array}{c}\text { Coal (GUS } \\
\text { and GMS) } \\
1.6\end{array}$} & \multirow{2}{*}{$\begin{array}{r}\text { Faults } \\
2.5\end{array}$} \\
\hline \multirow{12}{*}{ 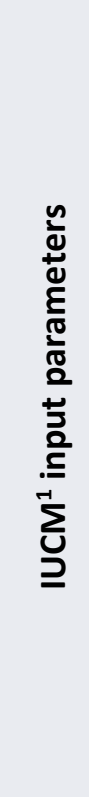 } & Density $\left(t / m^{3}\right)$ & & & \\
\hline & $\mathrm{Ei}^{2}(\mathrm{GPa})$ & 6.3 & 2.5 & 2.5 \\
\hline & $\operatorname{Sigci}^{3}$ (MPa) & 26 & 8.7 & 26 \\
\hline & $\mathrm{mi}^{4}$ & 7.5 & 15 & 7.5 \\
\hline & Anisotropy factor ${ }^{5}$ & 2.0 & 2.0 & 2.0 \\
\hline & $\operatorname{Dip}^{6}\left({ }^{\circ}\right)$ & 3 & 3 & 3 \\
\hline & Dip direction ${ }^{7}\left({ }^{\circ}\right)$ & 90 & 90 & 90 \\
\hline & $\mathrm{GSI}^{8}$ & 55 & 50 & 30 \\
\hline & $\mathrm{CRes}^{9}$ (Mpa) & 0 & 0 & 0 \\
\hline & FriRes $^{10}$ (Mpa) & 30 & 30 & 30 \\
\hline & TenRes $^{11}$ (Mpa) & 0 & 0 & 0 \\
\hline & CritRed $^{12}$ & 1.5 & 1.5 & 1.5 \\
\hline
\end{tabular}

GUS - Goonyella Upper Seam. GMS - Goonyella Middle Seam. ${ }^{1}$ Improved Unified Constitutive Model. ${ }^{2}$ Elastic modulus of intact rock (obtained from laboratory test results). ${ }^{3}$ Unconfined compressive strength (UCS) of intact rock (obtained from laboratory test results). ${ }^{4}$ Hoek-Brown constant (obtained from UCS/ultimate tensile strength (UTS), no triaxial testing data was available). ${ }^{5}$ Anisotropy factor (obtained from published data). ${ }^{6}$ Dip angle of bedding plane (obtained from structural information but adjusted during model calibration). ${ }^{7}$ Dip direction of bedding plane (obtained from structural information but adjusted during model calibration). ${ }^{8}$ Geological Strength Index (Estimated based on reported joint spacing values). ${ }^{9}$ Residual cohesion. ${ }^{10}$ Residual friction angle (adjusted during model calibration). ${ }^{11}$ Residual tensile strength. ${ }^{12}$ Reduction factor for critical strain (adjusted during model calibration). 
Three mining steps were simulated in the back-analysis, following an initial mining state, as shown in Figure 6.
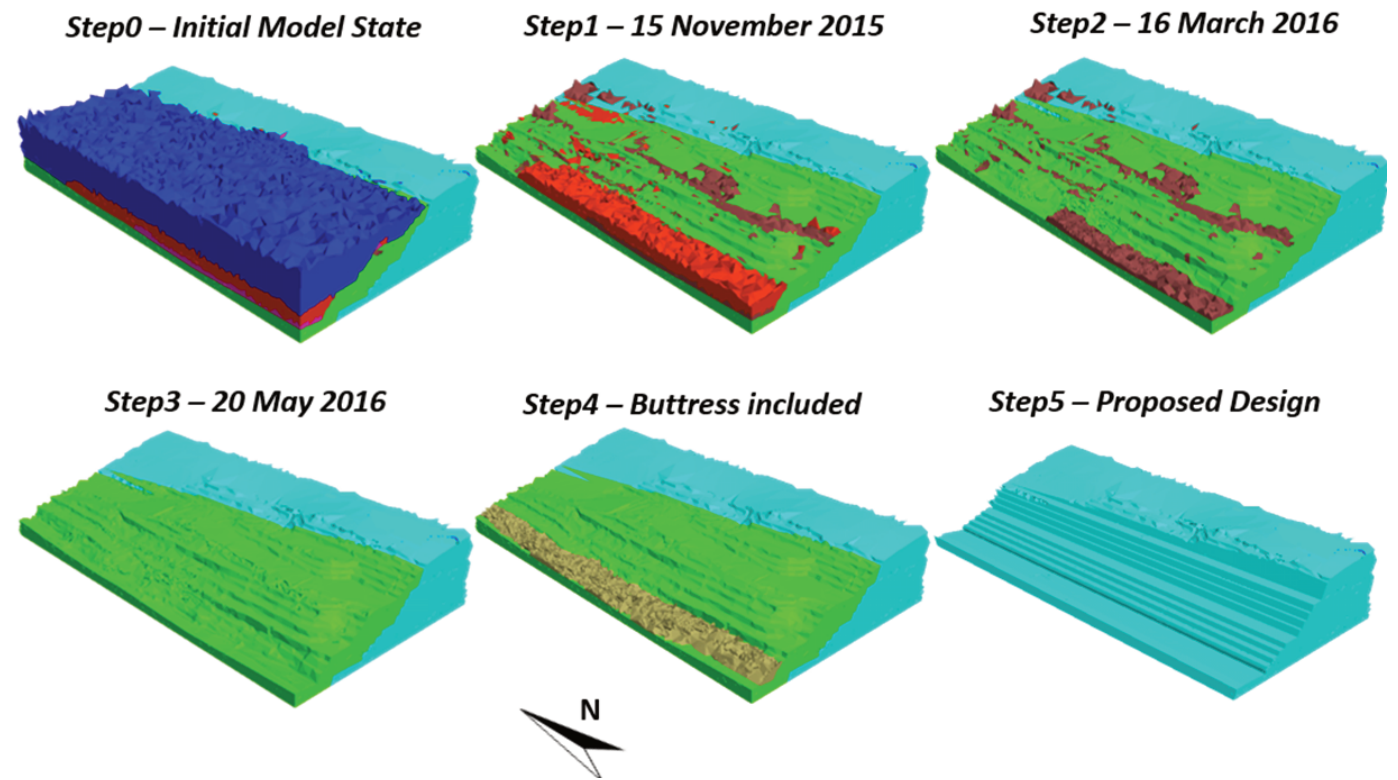

Step5 - Proposed Design

Figure 6 Ramp 12 highwall slope numerical model steps

The back-analysis results shown in Figure 7 indicated that early deformation was associated with the thrust fault's intersection with the highwall. Displacements were concentrated at the toe of the failure and the modelled area of displacement correlated well with the observed failure area. This result provided an excellent starting point for modelling predictive scenarios for slope stabilisation and future design. A comparison of back-analysis derived deformation to the actual slope deformation from LiDAR survey data provided a reliable match of predicted to actual in terms of location of slope deformation and amount of movement.
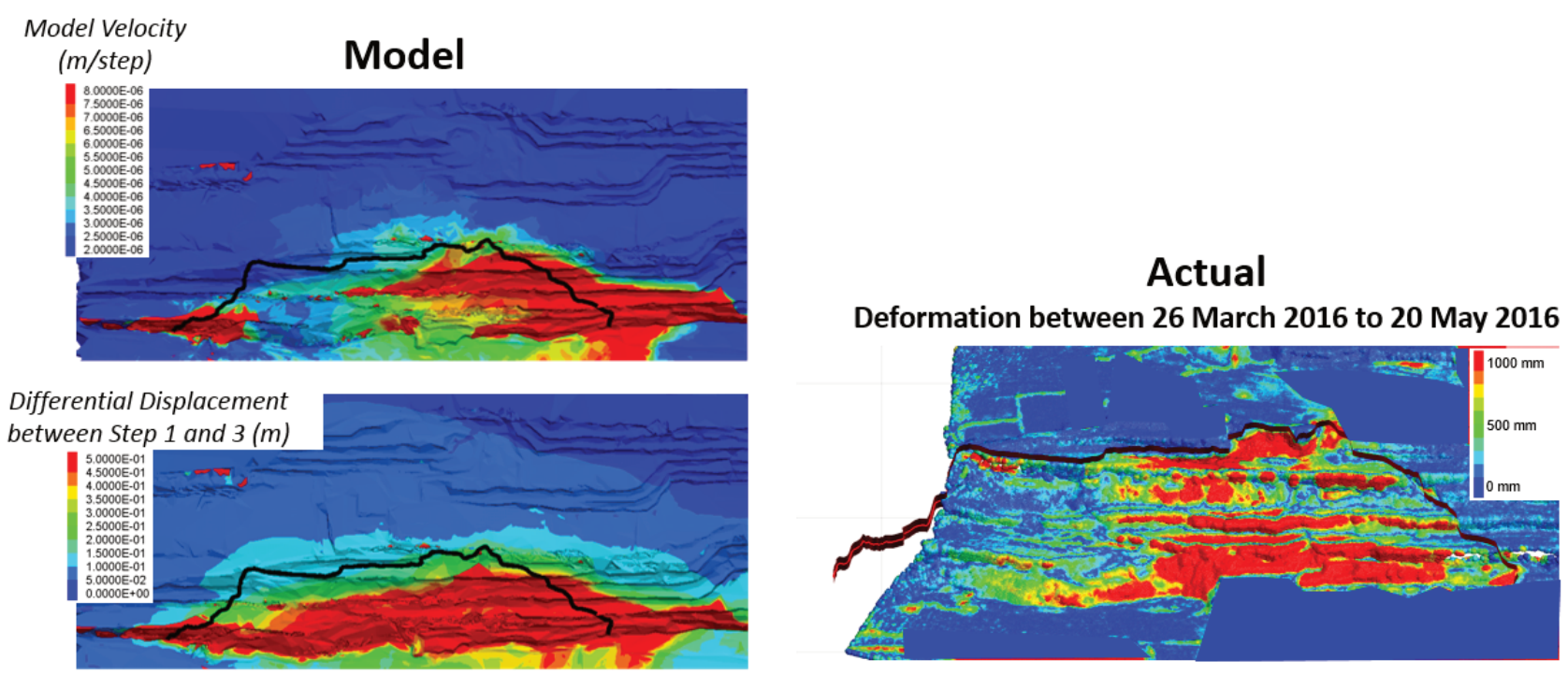

Differential Strain

between Step 1 and 3

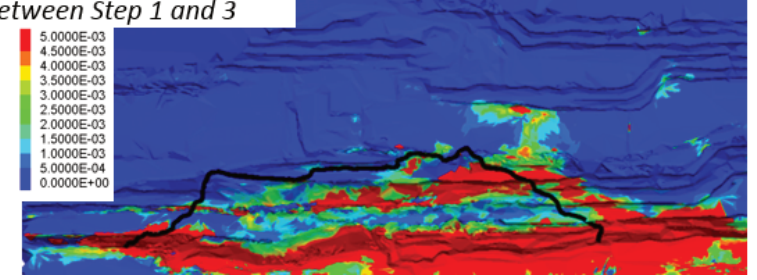

Figure 7 Ramp 12 highwall slope failure back-analysis model, perspective view 


\subsection{Buttress construction}

There are a number of ways that a buttress could conceptually be constructed on the GMS level at the toe of the failure. Regardless of the placement method, the buttress was required to ensure stability while mining. If material can be thrown over the face of the failure, rill slopes can form which can assist with managing the risk of crest failure while mining. Limit equilibrium methods (general limit equilibrium/Morganstern Price) were used to quickly establish a possible minimum buttress size for failure stabilisation, before using a three dimensional numerical approach (FLAC3D with IUCM) to optimise and confirm. Limit equilibrium methods were not going to provide the final and accepted solution without further checks for a number of reasons. Two of the more important reasons are that the failure path is chosen by the user, rather than letting the numerical model calculate the failure path and a progressive failure is unable to be assessed. In the case of the Ramp 12 highwall failure, the failure was progressive and a numerical modelling technique that was able to account for ongoing deformation, strength and stress changes was required. In this case, limit equilibrium methods are therefore used as guidance, rather than for definitive solutions.

The initial limit equilibrium stability assessment indicated a $30 \mathrm{~m}$ high and $40 \mathrm{~m}$ wide toe buttress was required to stabilise the overall slope deformation. The three dimensional numerical model used in the back-analysis was extended to add the buttress. It demonstrated the buttress size was suitable in slowing the overall slope deformation, although localised shallow slope deterioration was expected to continue on a batter scale, as shown in Figure 8.
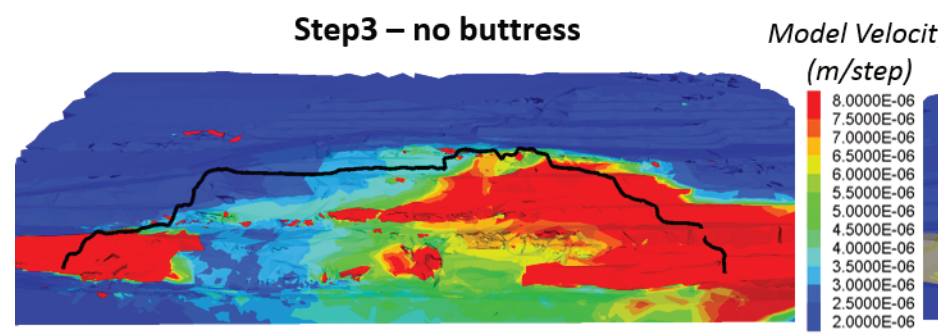

Step4 - buttress included
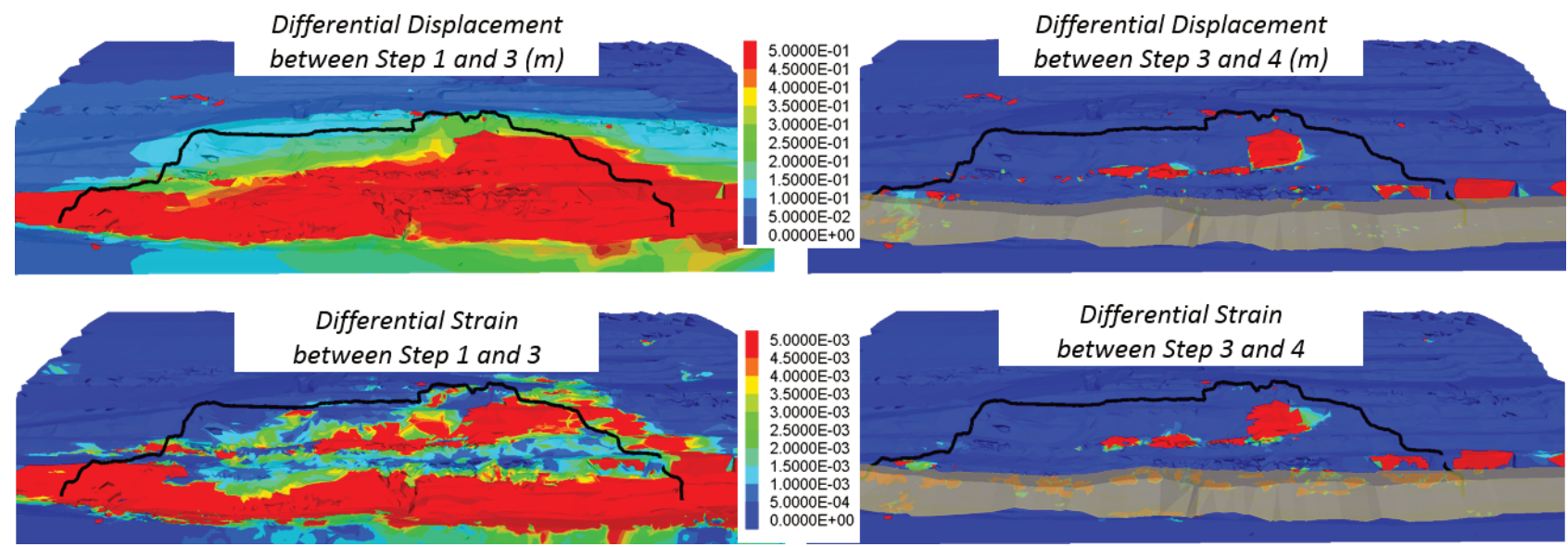

Figure 8 Pre- and post-buttress slope failure deformation

Radar monitoring was continued during buttress construction to ensure the movement in the slope above the buttress was being controlled or halted as the buttress advanced along the GMS bench.

\section{$4 \quad$ Forward assessment for further mining}

The highwall slope design for the next strip position needed to consider the important factors that made significant contribution to the original failure, being the overbank structures and the thrust fault. The thrust fault was interpreted to possibly remain influential on stability and was positioned much lower in the slope. 
The overbank structures, having also played a contributing role, were assessed to check their ongoing influence on the future slope position. Mapping data from laser scanning and field mapping clearly showed the overbank structures dipping into the pit void and bedding orientations from drillhole acoustic televiewer files located immediately behind the failure showed the ongoing concentration of overbank structures, concentrated in the vicinity of the failure, as shown in Figure 9.

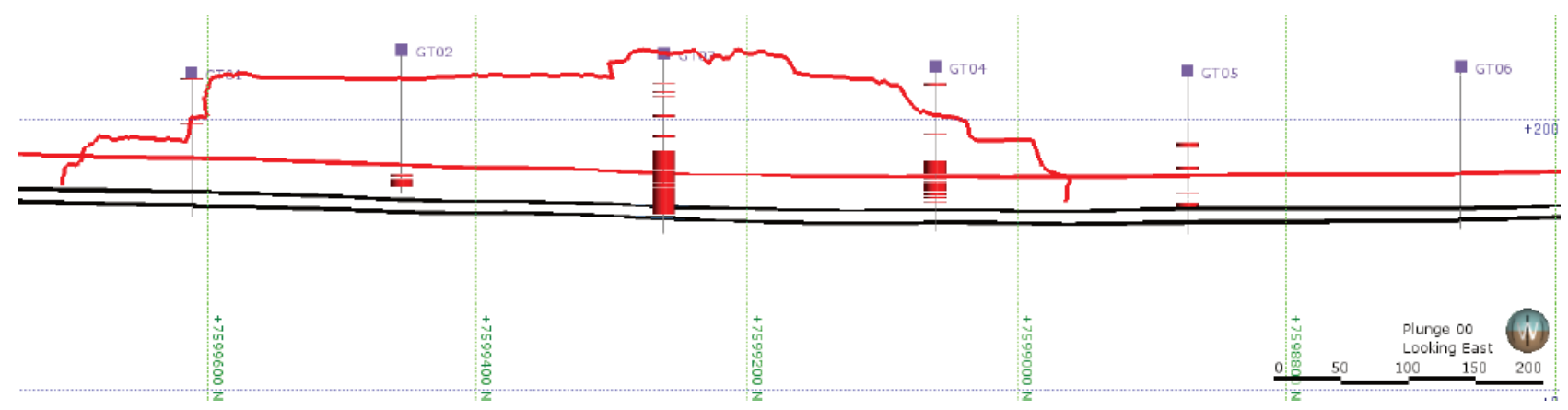

Figure 9 Acoustic televiewer data showing dip direction - red indicate dip direction $230^{\circ}$ to $270^{\circ}$ (dipping into the pit at dips $\geq 15^{\circ}$ )

A conceptual Ramp 12 slope design was developed and assessed in the same three dimensional numerical model. A feature of this slope was an optimised $40 \mathrm{~m}$ wide offset distance in the Permian material, as shown in Figure 10. This was intended to unload the overbank structures which were present in the next highwall and improve highwall stability performance.

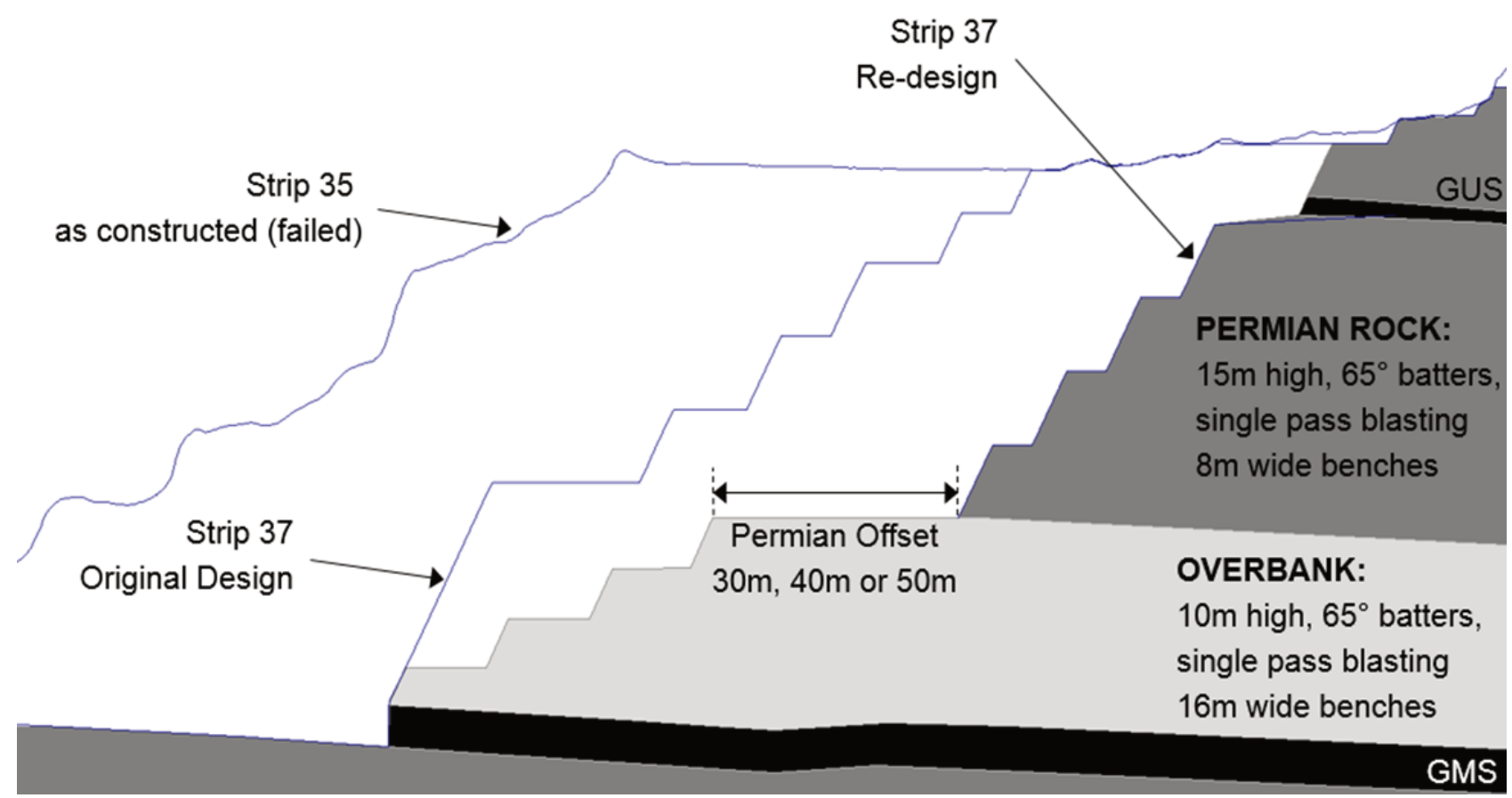

Figure 10 Redesigned Ramp 12 highwall

Modelling predicted batter scale failure and some multi batter failures were indicated, but deep seated or overall slope failure remained above a Factor of Safety of 1.2, as shown in Figure 11. 


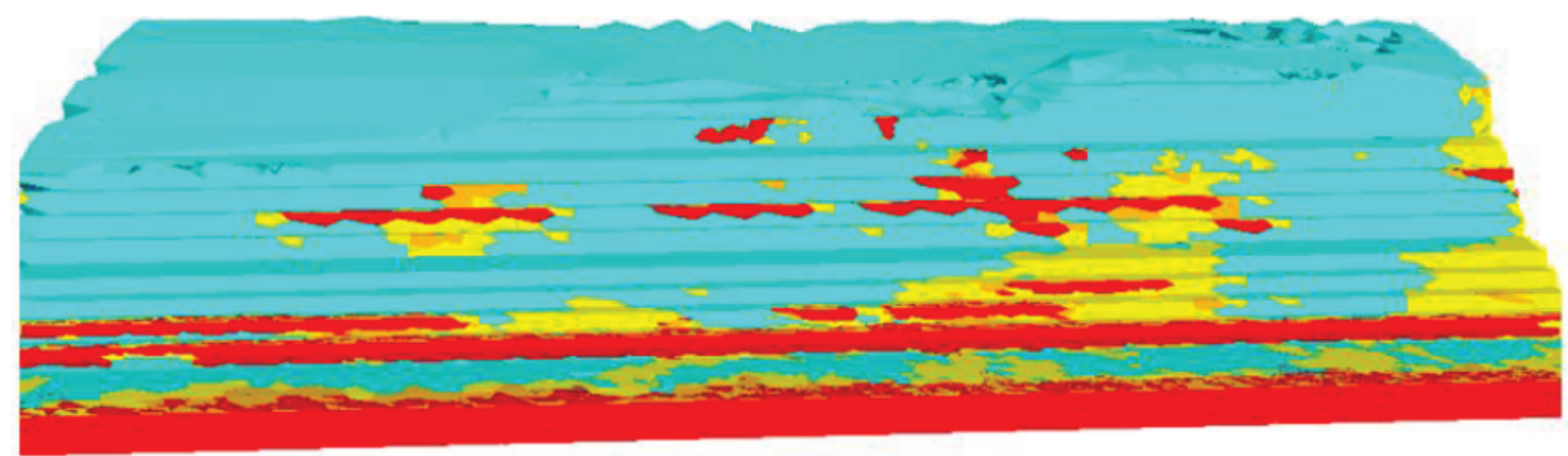

Figure 11 Numerical stability model results for the redesigned highwall, perspective view

Instability of the slope in the next strip was accurately predicted by the modelling. While the overall slope performed well, multi batter instability to the top of the overbank bedding domain was observed in the area where the old failure scarp was not fully mined out in the designed softwall above coal. The observed instability was then managed by radar monitoring and block by block mining to recover the majority of the planned GMS coal, without significant additional pre-strip from natural surface.

\section{Conclusion}

A highwall slope failure was monitored and safely managed at Ramp 12 during 2016, when engineering geology investigations commenced to determine the mechanism of slope movement. The slope failure was attributed to a number of structural influences, including overbank bedding structures and thrust faulting with the mechanism being a composite failure. Despite the relatively large-scale of failure, coal production was safely continued with effective monitoring controls in place. The failure was stabilised by a $30 \mathrm{~m}$ high and $40 \mathrm{~m}$ wide slope buttress, that was justified by a three dimensional numerical model using the IUCM solver and the slope was mined by the pre-strip truck and shovel fleet. A back-analysis approach was able to show the progressive nature of the failure and match the extent of failure along the highwall, with the introduction of the thrust fault failing in combination with overbank structures.

The slope was redesigned for the next highwall strip position to account for the identified failure mechanism. The upper Permian material was offset $40 \mathrm{~m}$ to the east, to achieve an acceptable overall slope Factor of Safety, but still predicted some batter scale and multi batter failure. The actual stability performance of the redesigned slope was accurately predicted by the modelling and allowed for safe mining to continue.

\section{References}

Simmons, JV \& Simpson, PJ 2006, 'Composite failure mechanism in coal measures rock masses - myths and reality', The Journal of the South African Institute of Mining and Metallurgy, vol. 106.

Vakili, A, Albrecht, J \& Sandy, M 2014, 'Rock strength anisotropy and its importance in underground geotechnical design', Proceedings of the Third Australasian Ground Control in Mining Conference (AusRock) The Australasian Institute of Mining and Metallurgy, Melbourne, pp. 167-180.

Vakili, A 2016, 'An improved unified constitutive model for rock material and guidelines for its application in numerical modelling', Computers and Geotechnics, vol. 80, pp. 261-282. 
